\title{
The haloacetic acids formation potential in treated waters exposed to ozone and chlorine
}

\author{
Shangchao Yue ${ }^{1, ~ a, ~ L e j u n ~ Z h a o ~}{ }^{1, b}$, Xiuduo Wang ${ }^{1, c}$, \\ Qishan Wang ${ }^{2, \mathrm{~d}}$ and Fenghua $\mathrm{He}^{3, \mathrm{e}}$ \\ ${ }^{1}$ Tianjin Municipal Engineering Design and Research Institute, Tianjin 300392, PR China \\ ${ }^{2}$ College of environmental science and engineering, Nankai University, Tianjin 300071, PR China \\ ${ }^{3}$ Tianjin TEDA water supply company, Tianjin 300457, PR China \\ aysc010@163.com, blejun-zhao@vip.sina.com, cwang_xiuduo@eyou.com, \\ dwangqsh@nankai.edu.cn, ehefenghua121@sina.com
}

Keywords: Preozonation; Prechlorination; HAAs; Full-scale.

Abstract. The objectives of this study were implemented to investigate the haloacetic acids formation potential (HAAFP) in drinking water treatment and determine the reduction of haloacetic acids (HAAs) during preozonation. This full-scale examination was conducted with Luan River water. Two preoxidation methods were performed, prechlorination and preozonation. HAAFP and HAA species were analyzed. The investigation indicated that $33.25 \%$ of HAAFP was removed during preozonation. Study on the distribution of HAA species showed a significant reduction during preozonation, $21.52 \%$ of DCAA, $66.20 \%$ of TCAA and $42.59 \%$ of DBAA was removed, respectively. The result suggested that preozonation process is effective to reduce HAAs generation during the treatment. In the final effluent, the total removal rate of HAAFP was $67.79 \%$.

\section{Introduction}

Natural organic matter (NOM) in source waters may react with chlorine to form a series of disinfection by-products (DBPs) during disinfection. Trihalomethanes (THMs) and haloacetic acids (HAAs), the major DBPs, are established to be mutagens, carcinogens and toxicants [1-3]. For the concerns on public health risks, the water treatment plants have to optimize treatment processes or adopt new technology to meet the balance between disinfection and DBPs.

Ozone is the strongest, fastest-acting oxidant of the disinfectants [4] and it has been considered an alternative disinfectant. It had been reported that ozonation can reduce DBP formation potential (DBPFP) [5-7]. Yet, the opposite result had also been observed [8-10].

Most of the former studies were carried out in lab-scale or pilot-scale and few studies were available regarding the removal of DBPFP in full-scale plants. Furthermore, very little research had been conducted on the comparison of the DBP formation after prechlorination or preozonation.

This full-scale research presented goes beyond previous studies and was carried out in a water supply plant. The primary aim of this study was to compare the treatment efficacy of preozonation and prechlorination, in terms of concentration changes of DOC, $\mathrm{UV}_{254}$, SUVA and subsequent minimization of DBPFP from the source water in North China.

\section{Materials and methods}

Source water characterization. In this full-scale study, raw water was from the Luan River. In winter, the water is characterized by low temperature and turbidity.

Treatment processes. This study was carried out in a water supply plant in Tianjin. The processes were preoxidation (preozonation or prechlorination), coagulation, clarification, filtration and final disinfection, presented in Fig. 1 . About $1.0 \mathrm{mg} / \mathrm{L}$ of ozone or chlorine were added during preoxidation. The contact time was controlled at three minutes [11]. 


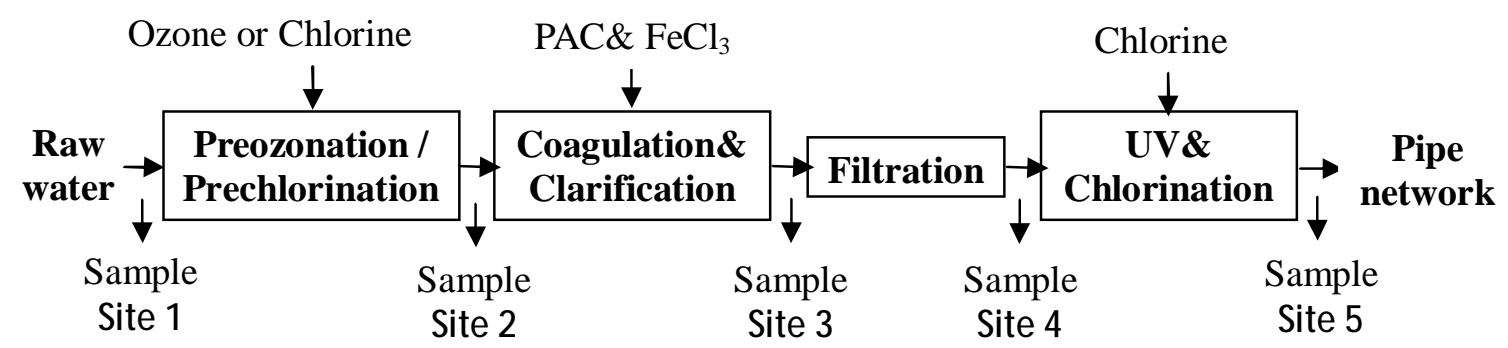

Fig.1 Schematic diagram of treatment processes

\section{Analysis.}

One milliliter samples were analyzed for Five HAAs, i.e., monochloroacetic acid (MCAA), monobromoacetic acid (MBAA), dichloroacetic acid (DCAA), dibromoroacetic acid (DBAA) and trichloroacetic acid (TCAA). HAAs was detected by gas chromatograph (GC) under USEPA Method 552.3 (USEPA, 2003).

\section{Results and discussion}

Raw water characteristics. In the raw water, turbidity was 7.02 - 17.9 NTU, temperature was 4 $14{ }^{\circ} \mathrm{C}$, pH was $8.03, \mathrm{UV}_{254}$ was $0.059 \mathrm{~cm}^{-1}$, DOC was $2.89 \mathrm{mg} / \mathrm{L}$, SUVA was $2.44 \mathrm{~L} /(\mathrm{mg} \cdot \mathrm{m})$ [11]. Table 1 Distribution of HAASFP in raw waters

\begin{tabular}{cccc}
\hline Parameter & $\begin{array}{c}\text { Measured range } \\
(\mu \mathrm{g} / \mathrm{L})\end{array}$ & $\begin{array}{c}\text { Meanconcentration } \\
(\mu \mathrm{g} / \mathrm{L})(\mathrm{n}=6)\end{array}$ & $\begin{array}{c}\text { Ratio } \\
(\%)\end{array}$ \\
\hline MCAA & ND & - & - \\
MBAA & ND & - & - \\
DCAA & $81.23-164.63$ & 131.63 & 60.75 \\
TCAA & $10.13-83.26$ & 41.30 & 18.55 \\
DBAA & $14.76-106.61$ & 43.82 & 20.70 \\
HAAFP & $177.04-277.36$ & 216.74 & \\
\hline
\end{tabular}

ND- Not detected

$\mathrm{n}$ - Number of samples

The distribution of haloacetic acid species formation potential (HAASFP) in the raw waters is shown in Table 1. DCAA formation potential was the predominant HAA compound, which accounted for $60.75 \%$ of HAASFP. Since no MCAA and MBAA were detected in raw water, DBAA and TCAA accounted for the other $20.70 \%$ and $18.55 \%$, respectively.

Reduction of HAAFP in different treatment processes. HAAs are a major group of DBPs in chlorinated water [12]. HAAFP along the treatment processes are presented in Fig.2. Comparison of the HAAFP decreases indicated that preozonation had a better and more stable reduction of HAAFP. $33.25 \%$ of HAAFP was removed from raw water during preozonation, while $30.77 \%$ of HAAFP during prechlorination. In the final effluents, greater decomposition of HAAFP was detected in Train 2 with a removal rate of $67.79 \%$, comparing to a decrease of $58.38 \%$ in Train 1 . The HAAFP concentrations were between 38.95 and $106.07 \mu \mathrm{g} / \mathrm{L}$ in six effluent samples. 


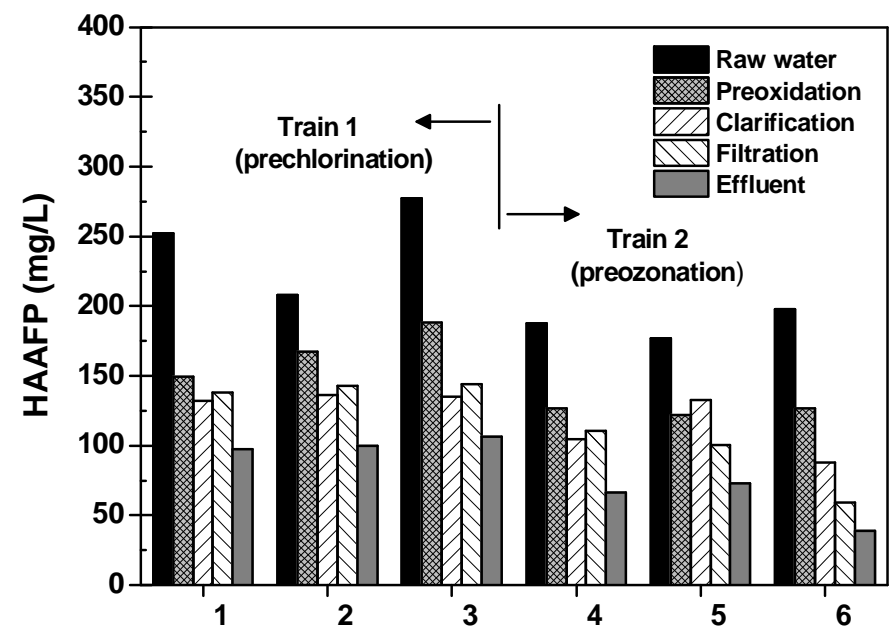

Fig. 2 HAAFP concentration changes along treatment processes

Further study on the distribution of HAASFP was carried out and five species of HAAs were also investigated. Since no MCAA and MBAA were detected in both treatment trains, the formation of other species (DBAA, TCAA and DCAA) are shown in fig. 3. After chlorination, $16.80 \%$ of DCAA, $49.04 \%$ of TCAA and $60.69 \%$ of DBAA were removed from raw water, while $21.52 \%$, $66.20 \%$ and $42.59 \%$ were removed during preozonation, respectively, which suggested that ozone was more effective to reduce DCAA and TCAA than chlorine.

In final effluents, the total removal rates for DCAA, TCAA and DBAA in Train 1 were $49.75 \%$, $81.95 \%$ and $61.11 \%$, separately. Better reduction of HAASFP were achieved in Train 2, 53.45\% of DCAA, $98.70 \%$ of TCAA and $86.56 \%$ of DBAA were removed, respectively. Moreover, DCAA was the major HAA specie in the two treatment trains. The results suggested that ozone changed the structures of NOM during preozonation and HAA precursors were removed by the treatment processes.
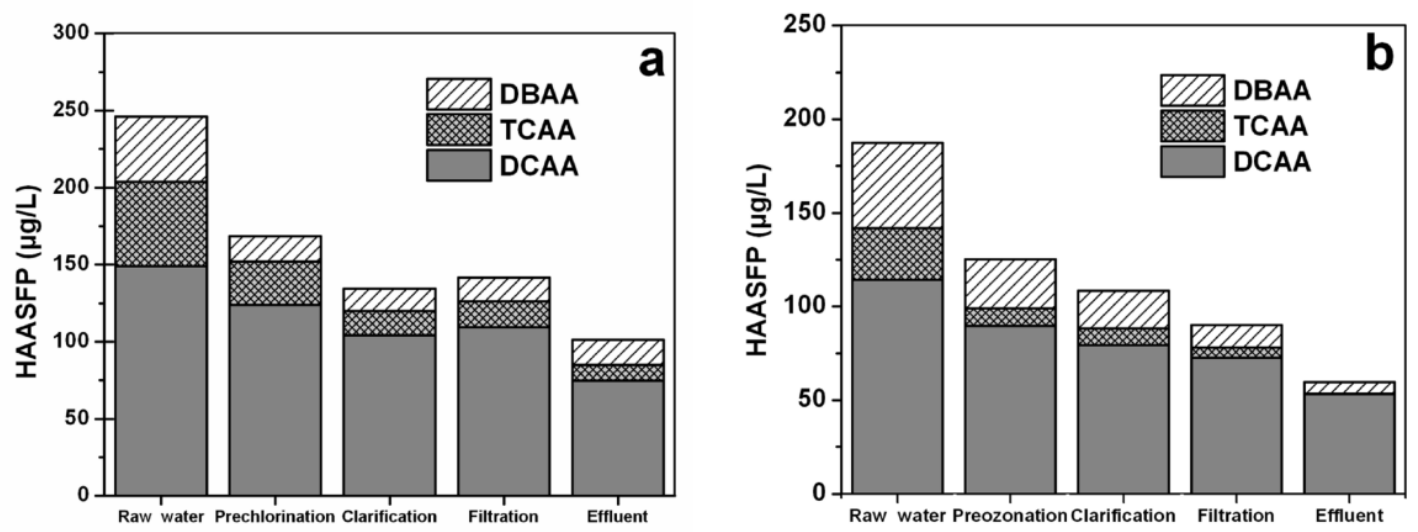

Fig. 3 The distribution of HAASFP along treatment processes

a)Train 1 with prechlorination, b) Train 2 with preozonation.

Comparing the reduction of THMFP [11] and HAAFP in the two treatment trains, the results indicated that HAAFP was removed better from raw water. Furthermore, preozonation was more effective at reducing HAAFP than THMFP in the period of this study, which showed a better removal of HAAs precursor materials during preozonation. The total removal rates also suggested a greater decomposition of HAAFP than THMFP, which may relate with the reduction of DBPFP during preoxidation. Since HAAFP values were higher than THMFP in raw waters and the health risk of HAAs is also higher than THMs, the removal of HAAFP was of great significance and the water quality had a great promotion. 


\section{Conclusions}

From the examination of HAAs in the Luan River water, we can find that DCAA was the major HAASFP, while no MCAA and MBAA were detected from the raw water.

Under a similar dosage of chlorine and ozone, preozonation performed better in the decrease of HAAFP than prechlorination, leading to a significant reduction of HAAFP. Approximately $68 \%$ of HAAFP in the raw water was removed after the Train 2 treatment.

Overall assessment of the results indicated that Train 2 treatment with preozonation was more effective in the removal of HAAs. The application of preozonation is an effective method for reducing DBP precursors in drinking water treatment. The introduction of preozonation in source waters treatment in China is feasible and it would be a substitute for prechlorination.

\section{Acknowledgements}

This study was financially supported by National Natural Science Foundation of China (51008162) Tianjin Science and Technology Research Projects (14TXSYJC00453) and Tianjin Science and Technology Research Projects (16YDLJSF00030).

\section{References}

[1] Singer, P.C.: J. Environ. Eng. Vol. 120 (1994), p. 727-744.

[2] Muellner, M.G., Wagner, E.D., Mccalla, K., Richardsen S.D., Woo Y.T. and Plewa M.J.: Environ. Sci. Technol. Vol. 41 (2007), p. 645-651.

[3] H. Komulainen: Toxicology Vol. 198 (2004), p. 239-248.

[4] G.H.R. Silva, L.A. Daniel, H. Buring and W.H. Rulkens: Bioresource Technol. Vol. 101(2010), p. 6981-6986.

[5] A. Teksoy, U. Alkan and H.S. Baskaya: Separation and Purification Technol. Vol. 61 (2008), p. 447-454.

[6] Guay C, Rodriguez M and S'erodes J.: Desalination Vol. 176(2005), p. 229-240.

[7] G.L. Amy, L. Tan and M.L. Davis: Wat.Res. Vol. 25 (1991), p. 191-202.

[8] Guanghui Hua and David A. Reckhow: Wat. Res. Vol. 41(2007), p. 1667-1678.

[9] R.R. Trussell and M.D. Umphres: J. AWWA. Vol. 70(1978), p. 604-602.

[10] M.S. Siddiqui, G.L. Amy and B.D. Murphy: Wat. Res. Vol. 31 (1999), p. 3098-3106.

[11] Shangchao Yue, Lejun Zhao, Xiuduo Wang, Qishan Wang and Fenghua He: Applied Mechanics \& Materials Vol. 700(2015), p. 542-546.

[12] Kunping Wang, Jinsong Guo, Min Yang and Rongsen Deng: J. Haz. Mat. Vol. 162(2009), p. 1243-1248. 